\title{
Single-Use Device Reprocessed and Reused on Patient
}

National Cancer Institute

\section{Source}

National Cancer Institute. Single-Use Device Reprocessed and Reused on Patient. NCI

Thesaurus. Code C53563.

An original device that has previously been used on a patient and has been subjected to additional processing and manufacturing for the purpose of an additional single use on a patient. The subsequent processing and manufacture of a reprocessed single-use device shall result in a device that is reprocessed within the meaning of this definition. A singleuse device that meets this definition should be considered a reprocessed device without regard to any description of the device used by the manufacturer of the device or other persons, including a description that uses the term recycled rather than the term reprocessed. 